\title{
Mass-length Relationships for 3 Bee Species in Northwest Ohio
}

JUSTIN D. BURDINE', ERIN PLUMMER, MELISSA SEIDEL, and KEVIN E. McCLUNEY, Department of Biological Sciences, Bowling Green State University, Bowling Green, OH, USA.

ABSTRACT. The ability to accurately estimate bee mass through measurements of intertegular distance (ITD) is an important tool for field biologists. ITD is the distance between the bases of the 2 wing tegulae on the bee's thorax. However, the relationship between ITD and bee mass can vary based on species and sampling region. A collection of 92 bees-representing 3 species-was examined to assess the accuracy of ITD in estimating dry mass for bees in northwest Ohio. The focus was on 3 species: silky striped sweat bees (Agapostemon sericeus), honey bees (Apis mellifera), and common eastern bumble bees (Bombus impatiens). Overall, there was a positive correlation between ITD and dry mass across all individuals sampled $\left(R^{2}=0.77\right)$, but within species the degree of correlation varied significantly. The results suggest that ITD accurately estimates dry mass in silky striped sweat bees $\left(R^{2}=0.93\right)$, but the correlation weakens in common eastern bumble bees $\left(R^{2}=0.54\right)$ and is non-existent in honey bees $\left(R^{2}=0.39\right)$. Field biologists interested in using ITD to estimate bee mass should take preliminary measurements when investigating bumble bees, and should avoid ITD estimates in honey bees.

\section{INTRODUCTION}

Increasing evidence suggests that bees (order: Hymenoptera) are in decline globally (Potts et al. 2010), but it is unclear whether these declines impact ecosystem services. Measures of functional diversity can be powerful tools in assessing whether services (e.g., pollination) will be maintained or disrupted. Recent studies have established libraries of bee functional traits, but certain traits are hard to measure in field studies. For example, bee body size (dry mass) is an important trait that is often used as a proxy for foraging distance (Greenleaf et al. 2007), and body size has a strong influence on which flowers bees pollinate (Peat et al. 2005). Accurate measurement of dry mass requires techniques that are lethal to the organism, and these techniques are difficult to accomplish in field studies.

Bee mass can be estimated using the length between the 2 wing tegulae (i.e., intertegular distance (or span; ITD)). Cane (1987) found intertegular distance to be highly correlated with dry mass across 20 solitary bee species. But there are drawbacks to the accuracy of ITD in estimating bee mass. First, it is unclear whether ITD is a good estimator of dry mass in eusocial species. Second, relationships between ITD and dry mass are strong when making interspecies comparisons, but weaken for intraspecies comparisons. Cane (1987) recommends taking preliminary measurements

${ }^{1}$ Address correspondence to Mr. Justin D. Burdine, Department of Biological Sciences, 217 Life Sciences Building, Bowling Green State University, Bowling Green, OH 43403-0208.

Email: jburdin@bgsu.edu of dry mass and ITD to estimate the strength of correlation, because these correlations are known to vary geographically (Martin et al. 2014). This study examined the accuracy of ITD in estimating dry mass for 3 bee species: silky striped sweat bees (Agapostemon sericeus), honey bees (Apis mellifera), and common eastern bumble bees (Bombus impatiens). These 3 species are common throughout northwest Ohio, and are important pollinators of wild and agricultural plants. It was predicted that correlations between ITD and dry mass would be strongest in silky striped sweat bees, because solitary species tightly regulate body size in relationship to ITD.

\section{METHODS AND MATERIALS}

Bees were sampled from 19 sites (parks, gardens) across the metropolitan region of Toledo, Ohio (USA) from June to August 2016. The bees in this collection were sampled using sweet nets, and specimens were stored in airtight vials (PELCO ${ }^{\circledR}$ Mini Vials). This collection included 18 silky striped sweat bees (A. sericeus), 22 honey bees ( $A$. mellifera), and 52 common eastern bumble bees (B. impatiens). The collection currently resides at Bowling Green State University. Intertegular distance was measured as the shortest span between the 2 tegulae using digital vernier calipers (BioQuip ${ }^{\circledR} \# 1$ 164D) with an

\footnotetext{
C 2018 Burdine et al. This article is published under a Creative Commons Attribution 4.0 International License ( https://creativecommons.org/licenses/by/4.0/ )
} 
accuracy of $\pm 0.02 \mathrm{~mm}$. Dry mass was calculated by placing samples into a drying oven (Fisherbrand ${ }^{\mathrm{TM}}$ Gravity Oven, Catalog No. 15-103-0520) set to $55^{\circ} \mathrm{C}$ for 48 hours, and dried specimens were weighed using a micro balance (METTLER TOLEDO ${ }^{\circledR}$ XPE56) with a readability of 1 microgram.

All statistical analyses were conducted in the program R (version 3.1.3), and the "nlme" package was utilized to fit linear mixed-effects models ("lme"). The relationship of ITD and dry mass was calculated for all individuals in the collection. Site identification was included as a random effect because multiple bees were collected at each site.
The significance of fixed effects was tested with likelihood ratio tests where main effects are removed from the model (Bolker et al. 2009). $\mathrm{R}^{2}$ (coefficient of determination) values were calculated using the

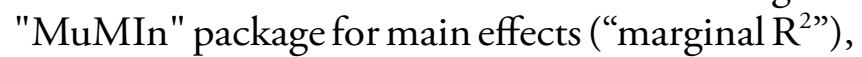
and main effects with site ID included ("conditional

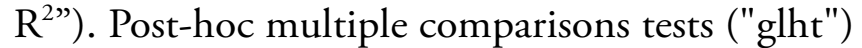
were conducted to test relationships within species (sweat bees, bumble bees, honey bees) following significant main effects using the "multcomp" package. Plots of residuals were examined to check that assumptions of normality and equal variance were met.

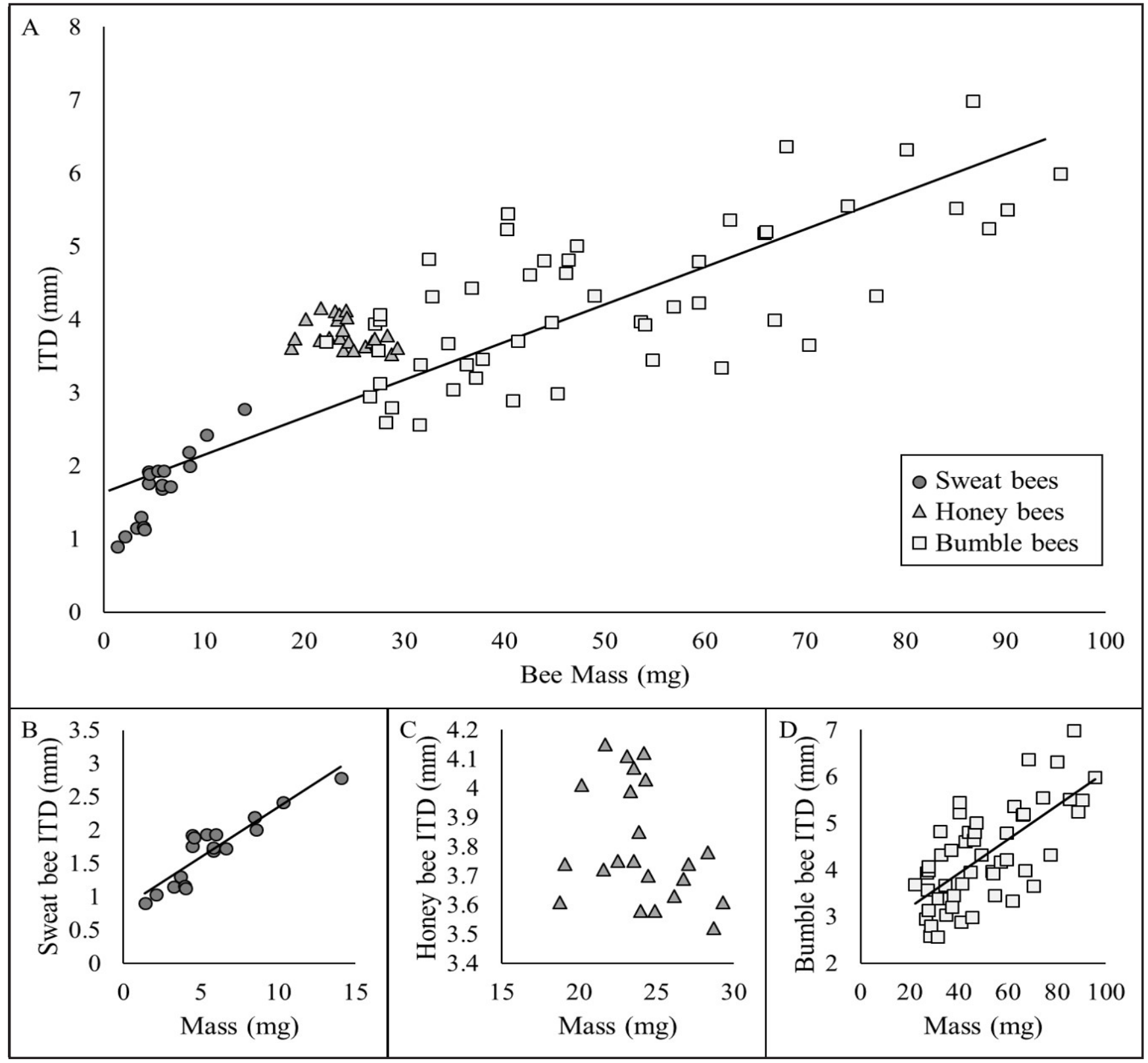

FIGURE 1. Relationship between intertegular distance (ITD) and dry mass across and within species. (A) ITD was significantly associated with dry mass for all individuals sampled $\left(p<0.001, R^{2}=0.77\right)$. (B) Sweat bee ITD was significantly associated with dry mass $\left(p<0.001, R^{2}=0.93\right)$. (C) Honey bee ITD was not associated with dry mass $\left(p=0.17, R^{2}=0.39\right)$. (D) Bumble bee ITD was significantly associated with dry mass $\left(p<0.001, R^{2}=0.54\right)$. This figure reports conditional $R^{2}$ values. 


\section{RESULTS}

Significant differences were detected in dry mass between species $\left(\mathrm{df}=2, \chi^{2}=88.03, \mathrm{p}<0.001\right)$ : bumble bees $(\bar{x}=49.8 \mathrm{mg}, s=19.7)$ were the largest species, followed by honey bees $(\bar{x}=24.1 \mathrm{mg}, s=0.6)$ and striped sweat bees $(\bar{x}=5.7 \mathrm{mg}, \mathrm{s}=0.7)$. A significant relationship was found between ITD and dry mass $\left(\mathrm{df}=1, \chi^{2}=75.63, \mathrm{p}<0.001 ;\right.$ marginal $\mathrm{R}^{2}=0.62$, conditional $\mathrm{R}^{2}=0.77$; Fig. $1 \mathrm{~A}$ ).

Post-hoc tests were conducted to investigate the strength of relationships within species. A strong positive relationship was found between dry mass and ITD for striped sweat bees $\left(\mathrm{df}=1, \chi^{2}=34.84\right.$, $\mathrm{p}<0.001$; marginal $\mathrm{R}^{2}=0.83$, conditional $\mathrm{R}^{2}=0.93$; Fig. 1B), and a moderately positive relationship for bumble bees $\left(\mathrm{df}=1, \chi^{2}=32.13, \mathrm{p}<0.001\right.$; marginal $\mathrm{R}^{2}=0.45$, conditional $\mathrm{R}^{2}=0.54$; Fig. $\left.1 \mathrm{D}\right)$. There was no relationship between mass and ITD for honey bees $\left(\mathrm{df}=1, \chi^{2}=1.882, \mathrm{p}=0.17\right.$; marginal $\mathrm{R}^{2}=0.06$, conditional $\mathrm{R}^{2}=0.39$; Fig. $1 \mathrm{C}$ ).

\section{DISCUSSION}

There was a strong positive relationship between intertegular distance (ITD) and dry mass in striped sweat bees and a moderately-strong positive relationship in bumble bees. No relationship was found between mass and ITD in honey bees. The strength of relationship in striped sweat bees (conditional $\left.\mathrm{R}^{2}=0.93\right)$ is comparable to the results that Cane (1987) found in a study of 20 solitary bee species $\left(R^{2}=0.96\right)$. Variation in body size may impact fitness more strongly in solitary bees like striped sweat bees, thus these species should exhibit a tight regulation of body size in relation to ITD. Field biologists interested in using ITD to estimate dry mass should be confident when making comparisons with sweat bees, cautious when making comparisons with bumble bees, and should avoid using ITD to estimate dry mass in honey bees. Future investigations into honey bees and bumble bees should explore whether ITD and dry mass relationships differ by development stage or bee type (queens, workers, drones).

\section{LITERATURE CITED}

Bolker BM, Brooks ME, Clark CJ, Geange SW, Poulsen JR, Stevens MHH, White JSS. 2009. Generalized linear mixed models: a practical guide for ecology and evolution. Trends Ecol Evol. 24(3):127-135. https://doi.org/10.1016/j. tree.2008.10.008

Cane JH. 1987. Estimation of bee size using intertegular span (Apoidea). J Kansas Entomol Soc. 60(1):145-147. https:// www.jstor.org/stable/25084877

Greenleaf SS, Williams NM, Winfree R, Kremen C. 2007. Bee foraging ranges and their relationship to body size. Oecologia. 153(3):589-596. https://doi.org/10.1007/s00442-007$0752-9$

Martin CA, Proulx R, Magnan P. 2014. The biogeography of insects' length-dry mass relationship. Insect Conserv Diver. 7(5):413-419. https://doi.org/10.1111/icad.12063

Peat J, Tucker J, Goulson D. 2005. Does intraspecific size variation in bumblebees allow colonies to efficiently exploit different flowers? Ecol Entomol. 30(2):176-181. https://doi. org/10.1111/j.0307-6946.2005.00676.x

Potts SG, Biesmeijer JC, Kremen C, Neumann P, Schweiger O, Kunin WE. 2010. Global pollinator declines: trends, impacts, and drivers. Trends Ecol Evol. 25(6):345-353. https://doi. org/10.1016/j.tree.2010.01.007 